nuisance. Present conditions emphasize the wisdom of smoke abatement as a national defence measure. The national need for liquid fuel cannot, it is true, be met by the carbonization of coal, but the contribution is already by no means negligible. Already in 1938,8 per cent of the motor spirit consumed in Great Britain was obtained from coal. The quantity of heavier oil suitable as fuel was of the same order. The pamphlet makes a plea for a planned fuel policy, saying that "smoke is a by-product of the technologically primitive phase of industrial civilization from which we have not yet emerged".

\section{The Cooper Union}

THe eightieth annual report of the Cooper Union for the Advancement of Science and Art covers the year ended June 30, 1939 (Pp. 122. New York, 1939). The report of the Director, emphasizing the extent to which industry is becoming more scientific, refers to the increase in basic instruction in science and mathematics in the engineering schools, and decreased instruction in detailed applications of engineering. Special stress is laid in this report on the integrated study of the social sciences, so as to develop the mind of the engineering student not only to think rationally and scientifically, but also to be able to grasp concepts that do not admit of the precise analysis, calculation and control with which the physical scientist and engineer have been accustomed to work and which have hitherto been the accepted limit of his knowledge and proficiency.

The Director considers that humanistic studies should be required throughout the four or five years of undergraduate training. Commenting on our failure to stir those interests which lead the engineering graduate to continuing his studies of science and society, he urges that the impasse which faces civilization to-day is due to our attacking our problem by rule of thumb, expediency and self-interest, instead of by the scientific method, which, if coupled with sensitivity to the human values of freedom and individuality, will save civilization from the irresponsible technologist and the scheming politician.

\section{Control of Spirit}

Followrng the introduction of prohibition in Bombay, the Government has restricted sales, advertising and general dealing in all spirituous preparations containing more than 2 per cent by volume of alcohol. Recently, however, the Bombay Government has entirely exempted all toilet and cosmetic preparations containing alcohol from the prohibition regulations. It has also set up a Classification Committee to decide whether preparations which contain more than 2 per cent of alcohol can be used as beverages or not.

\section{Non-Ferrous Metallic Ores}

THE Minister of Supply has appointed a departmental committee to consider whether an increased production of non-ferrous metallic ores in the United Kingdom is desirable and practicable, and to make recommendations. The members of the committee are: Sir William Larke (chairman), Dr. C. G. Cullis, Mr. A.rthur Deakin, Mr. J. Stanley Holmes, M.P., and Mr. S. S. Taylor. Prof. J. A. S. Ritson, Mr. T. Eastwood, and Dr. M. Macgregor will act as assessors to the committee. The secretary of the committee, to whom all communications should be addressed, is Mr. W. C. C. Rose, Geological Surver of Great Britain, Exhibition Road, South Kensington, London, S.W.7.

\section{Colonial Appointments}

THe following appointments and promotions in the Colonial Service have recently been made: $\mathbf{H}$. $K$. Littlewood, veterinary officer, Nigeria; $R$. R. Temple, veterinary officer, Tanganyika Territory ; C. L. Skidmore, agricultural superintendent, senior agricultural superintendent, Gold Coast; Dr. F. Dixey, director of geological survey, Nyasaland, director, Water Development Department, Northern Rhodesia; H. R. Binns, formerly veterinary officer, Nyasaland, veterinary research officer, Palestine; R. Leach, mycologist, Nyasaland, plant pathologist, Jamaica (temporary).

\section{Announcements}

THE tenth Joule Memorial Lecture will be delivered before the Manchester Literary and Philosophical Society by Prof. James Chadwick, professor of physics in the University of Liverpool, on March 19 at 5.30. His subject will be "New Applications of Physics to Medicine".

Prof. F. L. WArren, formerly of the Fuad I University, Cairo, has been appointed professor of chemistry in the Natal University College, Pietermaritzburg.

THE fourth International Congress of Malaria will be held in Rome on the occasion of the International Exhibition of 1942 .

THE Australian Commonwealth Government has set up a Central Medical Co-administrative Committee at the seat of Government at Canberra. The Committee will control all drugs and medical equipment so as to ensure the best use for the armed forces and eivil population during war-time.

THE milk in schools scheme has been resumed for all children of school age, especially those in London. Voluntary milk clubs are being organized by teachers at schools and at certain other premises where children attend for some form of instruction. More than 200 of these clubs have already been formed and the number is growing almost daily. As in peace time, all children are asked to pay $\frac{1}{2} d$. for each half pint of milk.

Is the article entitled "Food Production and Food Control" by Sir John Orr published in Nature of March 9, p. 374, col. 2, last line of par. 3, the phrase " 10 and 20 per cent" should read " 5 and 10 per cent". This correction was received during the printing-off of the journal and was made in a part of the issue only. 